Original Research Article

\title{
Perception of doctors towards Adverse Drug Reaction (ADR) reporting: a cross sectional survey using a validated questionnaire
}

\author{
Nitin S. Kunnoor ${ }^{1}$, Sharanabasappa ${ }^{1}$, Lohit K. ${ }^{2 *}$
}

\begin{abstract}
${ }^{1}$ Department of Pharmacology, Mahadevappa Rampure Medical College and Hospital,

Kalaburagi, Karnataka, India

${ }^{2}$ Department of Pharmacology,

Sri Siddhartha Medical College,

Tumkur, Karnataka, India
\end{abstract}

Received: 13 September 2017

Accepted: 03 October 2017

*Correspondence to:

Dr. Lohit K.,

Email: lohitk4u@gmail.com

Copyright: (C) the author(s), publisher and licensee Medip Academy. This is an openaccess article distributed under the terms of the Creative Commons Attribution NonCommercial License, which permits unrestricted noncommercial use, distribution, and reproduction in any medium, provided the original work is properly cited.

\begin{abstract}
Background: Several studies have shown lack of sufficient knowledge and awareness among doctors on ADR reporting. Knowledge and attitude of doctors about ADR greatly influences extent of reporting. Identifying factors affecting ADR-reporting is vital to enable Pharmacovigilance teams to implement interventions to enhance rate and quality of reporting of ADRs. Hence, this study is done to evaluate perceptions of doctors towards ADR-reporting and to determine barriers for reporting ADR.

Methods: Cross sectional study conducted among doctors using a validated questionnaire to assess knowledge, attitude, practice and barriers for reporting ADRs. The questionnaire captured the demographic details, knowledge (14), attitudes (7) and practice pattern (4) towards pharmacovigilance. Descriptive statistics was used to assess the response among doctors.

Results: Of 157 doctors who responded to questionnaire, $90 \%$ of doctors were aware of pharmacovigilance program mainly through PVG activities by AMC and pharmacology classes. Only $47 \%$ doctors reported ADRs. The composite score on knowledge of ADR reporting and on knowledge of ADR burden was found to be moderate. $90 \%$ doctors opined ADR monitoring in hospital should be mandatory. $83 \%$ doctors opined ADR reporting by one person can make significant difference to community. One-third doctors felt there should be financial reward for ADR-reporting. In suspected cases, 57\% doctors include ADR as differential diagnosis. $61 \%$ doctors said they will document ADR in patient file and $78 \%$ reports to AMC. More than one-third doctors don't know where and how to report ADR. One-third doctors felt management of patients was more important than reporting ADR. Nearly one-fourth didn't report fearing legal liabilities, difficulty diagnosing ADR and negative impact on doctors.

Conclusions: Knowledge about ADR-reporting and attitude towards it is adequate. But, because of many barriers, actual practice of ADR-reporting is unsatisfactory. Hence, Pharmacovigilance training is essential for doctors to promote and improve ADR-reporting.
\end{abstract}

Keywords: Adverse Drug Reaction (ADR), Attitude, Knowledge, Doctors, Practice

\section{INTRODUCTION}

Adverse drug reactions (ADR) are an important public health problem in terms of mortality, morbidity as well as costs. ADR is defined by $\mathrm{WHO}$ as a response to drug which is noxious and unintended and that occurs at doses normally used in man for prophylaxis, diagnosis or therapy of disease or for modification of physiological function. ${ }^{1}$ Pharmacovigilance is the science and activities related to detection, assessment, understanding and prevention of adverse effects. $^{2}$

ADR monitoring helps to detect new, serious and even unknown reactions. Reporting of known ADRs helps to 
establish the frequency of occurrence and identifies risk factors which may be predictable. By adding onto the existing database, it helps in signal detection. This enables regulatory agencies to formulate drug use guidelines, issue warnings or even ban/withdraw the drug from the market.

Spontaneous reporting plays a major role in the detection of ADRs by health care professionals (HCP) and a constant effort has been put by the concerned authorities in reinforcing reporting practices. However, studies worldwide have shown gross under reporting with a rate of around $9.4 \%$. $^{3,4}$

Several studies have shown lack of sufficient knowledge and awareness among health care professionals on ADR reporting as an important factor. A systematic review conducted across the globe has found an alarming rate of 95\% of under-reporting were ignorance, diffidence and lethargy in $72 \%$ and $77 \%$ each. ${ }^{5}$ Educational interventions such as CMEs, conference, lectures on Pharmacovigilance for HCP, training workshops on ADR has found to improve the rate of reporting. ${ }^{6}$

Thus, identifying the factors affecting reporting is vital so as to enable the Pharmacovigilance teams to implement educational interventions to enhance the rate and quality of reporting of ADRs. Knowledge and attitude of health care professionals i.e. doctors about ADR greatly influences the extent of reporting. Hence, this study is being proposed to evaluate the perceptions of doctors about ADR reporting and assess the barriers of reporting ADR.

\section{METHODS}

This was a questionnaire based cross sectional study conducted among the doctors who have completed MBBS (physicians and postgraduates/tutors) at Mahadevappa Rampure Medical College and Hospital - a tertiary health care center. All the doctors working in the institution were included except those unwilling to participate.

\section{Study tool}

A validated questionnaire was used to assess knowledge, attitude, practice and barriers for reporting ADRs. ${ }^{7}$ This questionnaire captured the demographic details (age, sex, specialty and designation), their knowledge, attitudes and practice pattern towards pharmacovigilance. A total of 25 questions - 14 to evaluate the knowledge and burden of ADRs, 7 to know the attitude of doctors towards ADR reporting, 4 questions to assess the practice pattern.

For categorization of knowledge, composite score was derived and divided into three groups. Score $>66 \%$ was considered as adequate knowledge, 34-66\% was considered as moderate and $<34 \%$ was poor knowledge on ADR reporting. The attitudes question included opinions about reporting an ADR and includes the agreement towards preformed scale consisting of agree, disagree and don't know. The practice questions were intended to collect the information regarding the approach to ADR reporting in their clinical practice.

\section{Data collection}

Questionnaire was distributed to all the doctors after taking written consent. They are contacted on same day or after a day to collect the filled in questionnaire. Doctors not responding even after visiting five times personally were considered as non-responders.

\section{Statistical analysis}

Descriptive statistics was used for demographic data and to assess the response among doctors to identify knowledge, attitude of ADR reporting. Collected data was assessed by frequency, percentage, mean. Statistical analyses were performed using Statistical Package for the Social Sciences version 22.0 software (SPSS Inc, Chicago, IL, USA).

\section{RESULTS}

\section{Knowledge on ADR reporting}

A total of 157 doctors responded to the questionnaire. Majority doctors were males below 30 years of age and have less than 5 years of experience. $90 \%$ of the doctors were aware of the pharmacovigilance program mainly through PVG activities by ADR Monitoring Centre (AMC) and pharmacology classes during their academic sessions $(53 \%)$ followed by $\mathrm{CME}$ and orientation programs $(29 \%)$. (Table 1). The composite score on knowledge of ADR reporting $(53 \%)$ and on knowledge of ADR burden (39\%) was found to be moderate (Table 2).

Table 1: Demographic data.

\begin{tabular}{|c|c|c|}
\hline Parameters & Responses & $(\mathbf{N}=157) \mathbf{N}(\%)$ \\
\hline \multirow{2}{*}{ Gender } & Males & $106(67.5 \%)$ \\
\hline & Females & $51(32.5 \%)$ \\
\hline \multirow{3}{*}{ Age (years) } & $24-30$ & $100(63.7)$ \\
\hline & $31-40$ & $27(17.2)$ \\
\hline & $>40$ & $30(19.1)$ \\
\hline \multirow{3}{*}{ Experience (years) } & $0-5$ & $114(72.6)$ \\
\hline & $6-15$ & $25(15.9)$ \\
\hline & $16-25$ & $18(11.5)$ \\
\hline \multicolumn{2}{|c|}{ Designation: PG/tutor/residents } & $93(59.2)$ \\
\hline \multicolumn{2}{|l|}{$\mathrm{AP} / \mathrm{AsP} / \mathrm{P}$} & $64(40.8)$ \\
\hline \multicolumn{2}{|c|}{ Doctors aware of PVG } & $142(90.4 \%)$ \\
\hline
\end{tabular}

\section{Attitude on ADR reporting}

The 7 questions which assessed the attitude towards reporting of ADRs as summarized in Table 3. More than $90 \%$ the respondents were of the opinion that ADR monitoring should be mandatory in the hospital and one should be suspicious of possible ADRs caused by the 
particular drug. $84 \%$ of the doctors felt that ADR reporting by health care professional should be voluntary. $83 \%$ of the doctors opined that ADR reporting by one person can make a significant difference to the community. One third of the respondents agreed on financial rewarding for ADR reporting while other one third disagreed.

Table 2: Doctors knowledge on ADR reporting and ADR burden.

\begin{tabular}{|ll|}
\hline Parameters & Response \\
\hline $\begin{array}{l}\text { Knowledge of ADR reporting } \\
\text { Mean score } \\
\text { (Max. 21) }\end{array}$ & 11.06 \\
\hline $\begin{array}{l}\text { Burden of ADR reporting } \\
\text { Mean score (Max. 7) }\end{array}$ & 2.73 \\
\hline $\begin{array}{l}\text { Composite score } \\
\text { Knowledge of ADR Reporting (\%) }\end{array}$ & 52.65 \\
\hline $\begin{array}{l}\text { Composite score } \\
\text { Knowledge of Burden due to ADR (\%) }\end{array}$ & 39.04 \\
\hline
\end{tabular}

Table 3: Doctors attitude on ADR reporting.

\begin{tabular}{|c|c|c|c|}
\hline Attitude question & Response & $\begin{array}{l}\text { Numbers } \\
(\mathrm{n}=157)\end{array}$ & $\%$ \\
\hline \multirow{3}{*}{$\begin{array}{l}\text { One should be } \\
\text { certain of the ADR } \\
\text { due to particular } \\
\text { drug }\end{array}$} & Agree & 144 & 91.7 \\
\hline & Don't know & 11 & 7 \\
\hline & Disagree & 2 & 1.3 \\
\hline \multirow{3}{*}{$\begin{array}{l}\text { One should have a } \\
\text { suspicion of } \\
\text { possible ADR } \\
\text { during treatment }\end{array}$} & Agree & 147 & 93.6 \\
\hline & Don't know & 8 & 5.1 \\
\hline & Disagree & 2 & 1.3 \\
\hline \multirow{3}{*}{$\begin{array}{l}\text { ADR reporting by } \\
\text { one person can } \\
\text { make a significant } \\
\text { difference to the } \\
\text { community }\end{array}$} & Agree & 131 & 83.4 \\
\hline & Don't know & 13 & 8.3 \\
\hline & Disagree & 13 & 8.3 \\
\hline \multirow{3}{*}{$\begin{array}{l}\text { ADR reporting in } \\
\text { the hospital by } \\
\text { health care } \\
\text { professional should } \\
\text { be voluntary }\end{array}$} & Agree & 133 & 84.7 \\
\hline & Don't know & 17 & 10.8 \\
\hline & Disagree & 7 & 4.5 \\
\hline \multirow{3}{*}{$\begin{array}{l}\text { ADR reporting in } \\
\text { the hospital should } \\
\text { be mandatory }\end{array}$} & Agree & 141 & 89.8 \\
\hline & Don’t know & 12 & 7.6 \\
\hline & Disagree & 4 & 2.6 \\
\hline \multirow{3}{*}{$\begin{array}{l}\text { ADR reporting in } \\
\text { the hospital should } \\
\text { be financially } \\
\text { rewarded }\end{array}$} & Agree & 56 & 35.7 \\
\hline & Don't know & 51 & 32.5 \\
\hline & Disagree & 50 & 31.8 \\
\hline \multirow{3}{*}{$\begin{array}{l}\text { ADR reporting in } \\
\text { the hospital is not } \\
\text { required }\end{array}$} & Agree & 6 & 3.8 \\
\hline & Don't know & 7 & 4.5 \\
\hline & Disagree & 144 & 91.7 \\
\hline
\end{tabular}

\section{Practice and barriers on $A D R$ reporting}

$53 \%$ of the doctors did not report ADRs in their practice even thou they are aware of pharmacovigilance. $24 \%$ of the doctors have reported ADRs $1-3$ times. In suspected cases, $57 \%$ of the doctors declared that they include ADR as a differential diagnosis and $27 \%$ doctors rarely include it. Majority of the doctors said that they will document the ADR in patient file $(61 \%)$ and report it to AMC (78\%) if they come across any ADR (Figure 1 and Figure 2).

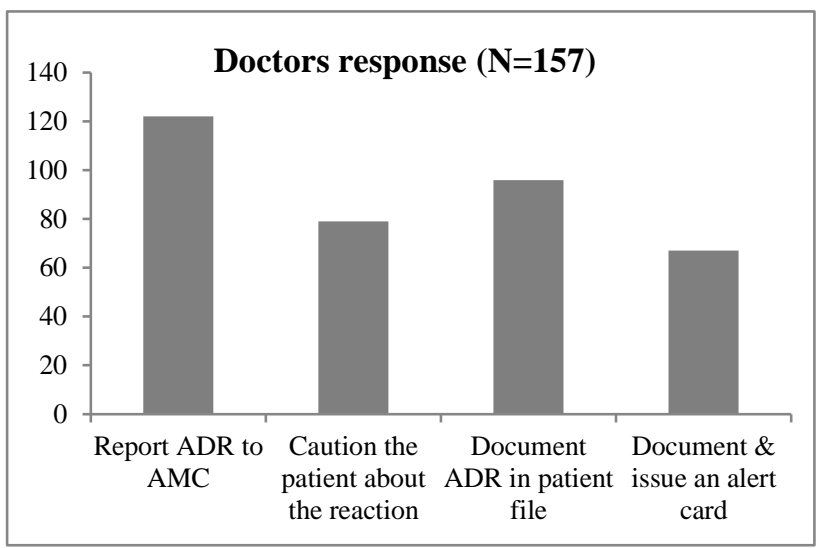

Figure 1: Doctors response when they come across ADR.

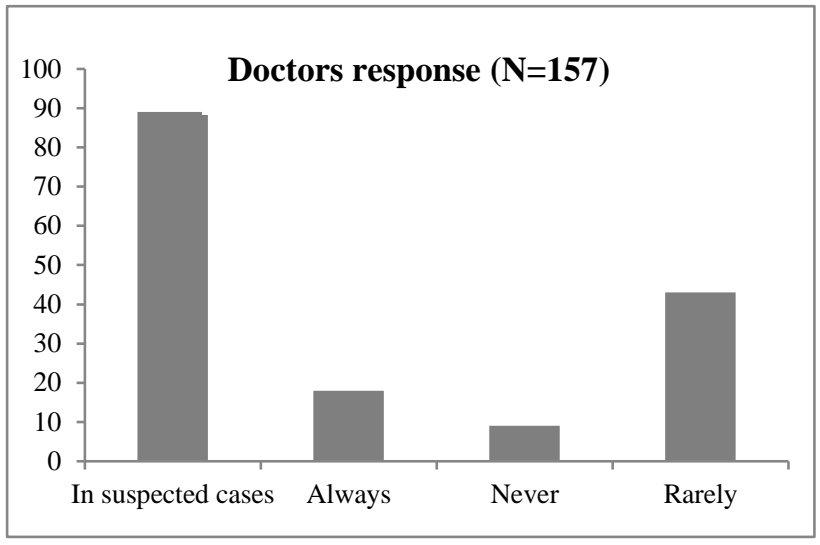

Figure 2: Frequency of considering ADR as differential diagnosis.

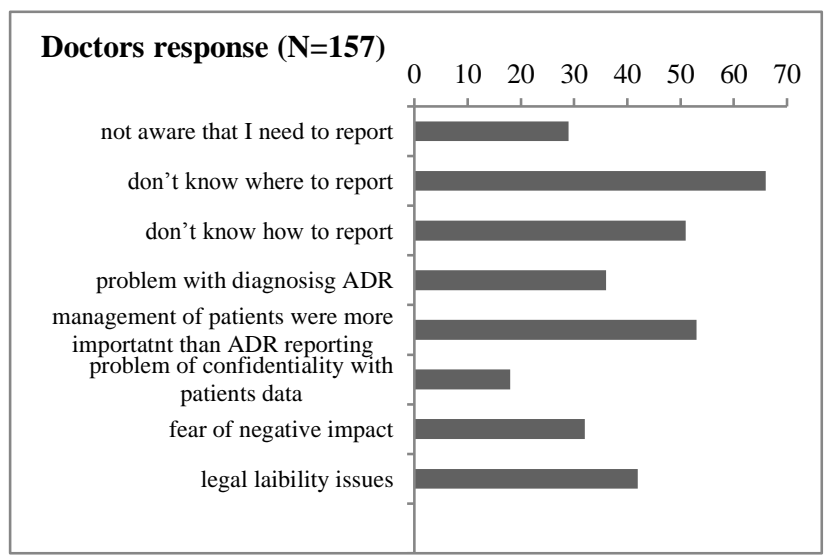

Figure 3: Barriers for ADR reporting.

More than one third of the doctors don't know where and how to report ADR ( $42 \%$ and $33 \%$ respectively) i.e; find the reporting form, how to fill it and to whom and how to 
send the reporting form. Management of patients was more important than ADR reporting (34\%). Some didn't report because of legal liabilities issues (27\%), difficulty with diagnosing ADR (23\%) and fear of negative impact on doctors (20\%) (Figure 3).

\section{DISCUSSION}

Under-reporting of ADRs is one of the main challenges in pharmacovigilance activities. Current spontaneous reporting and active surveillance has seen no improvememnt in the ADR reporting except few centres. Constant effort has been put by the concerned authorities in reinforcing reporting practices. ${ }^{8}$

Doctors play an important role in ADR reporting. Given their unique position in primary care of patients, they are often the first to be informed regarding any adverse reaction. They are thus an important source for identifying, recording and also cautioning the patient about possible ADRs.

Therefore it is essential to involve and train them on how and where to report the ADR. ${ }^{9}$ Our study has found moderate knowledge regarding ADR reporting, knowledge of ADR burden and unsatisfactory practice of the doctors. The average knowledge score of the respondents was $53 \%$ on ADR reporting and $39 \%$ on ADR burden, indicating that there is still much to be done to educate the doctors regarding ADR reporting. In contrast, studies done at different parts of India have shown high knowledge, but poor practice for ADR, among health care professionals. ${ }^{9-11}$

The results of the present study showed that most of the doctors had positive perception towards ADR reporting. The attitude level towards knowing the ADRs caused by the drugs, raising the suspicion on occurrence of ADRs, its reporting becoming mandatory and voluntary was the highest. Majority were of the opinion that ADR reporting can bring significant difference to the community. Previous studies have also identified ADR reporting as a professional obligation. ${ }^{8,12}$ ADR reporting as a professional obligation will have moral binding to healthcare professionals and ethical issues. The fact that one third of doctors believed that ADR reporting needs to be rewarded clearly shows the need for appropriate education and understanding the importance of this issue that will probably make a significant difference in reporting ADRs.

Actual practice of ADR reporting was unsatisfactory. 24 $\%$ of the doctors in our study had reported ADR similar to results of another study in which $25.6 \%$ of respondents had reported. ${ }^{13}$ Our study results are similar to previously reported studies where lack of training for clinical doctors on how to diagnose and report ADRs could be the probable reason for under reporting. ${ }^{14,15}$ Therefore, clinical sessions and training in hospitals through CMEs are necessary to train the doctors regarding ADR monitoring, diagnosing and reporting ADR. Patient counseling about occurrence of ADR and its reporting to health care professionals to be done regularly. This will strengthen the confidence of doctors; reduce the fear of negative impact and legal issues following the ADR in patients.

\section{CONCLUSION}

In conclusion, our study has shown that because of many barriers the actual practice of ADR reporting is unsatisfactory even though the doctors are aware of pharmacovigilance, and knowledge about ADR reporting and attitude towards it is adequate. Hence, it is essential to include pharmacovigilance training to the doctors to promote and improve reporting of ADR. Proper counseling of the patients regarding the medicines and possible ADRs will help prevent untoward events. Overall this will improve the pharmacovigilance activities.

\section{ACKNOWLEDGEMENTS}

Authors would like to acknowledge Ankush Kumar Mathapati, Ayesha Mansoor and Chetan Karkele, undergraduate students of MR Medical College, Kalaburagi for helping in data collection. Also, would like to thank all the doctors of the MR Medical College and Hospital, Kalaburagi for providing information.

Funding: No funding sources

Conflict of interest: None declared

Ethical approval: The study was approved by the Institutional Ethics Committee of MRMC (Ref. No: HKES/MRMCK/IEC/2015-09-01)

\section{REFERENCES}

1. Handbook of resolutions and decisions of the World Health Assembly and Executive Board WHA16.36 Clinical and Pharmacological Evaluation of Drugs, World Health Organization, Geneva; 1973: vol. 11948-1972.

2. Sachdev Y. Status of adverse drug reaction monitoring and pharmacovigilance in selected countries. Indian $\mathbf{J}$ Pharmacol. 2008;40:4-9.

3. Hazell L, Shakir SA. Under-reporting of adverse drug reactions: a systematic review. Drug Saf. 2006;29(5):385-96.

4. Shubha P, Jai Prakash R, Manjunath GN, Gautham MS, Naveen K. Adverse Drug Reaction reporting among medical and dental practitioners: a KAP study. Indian J of Med Spec. 2013;4(1):10-5.

5. Lopez - Gongalez E, Herdeiro MT, Figuerras A. Determinants of under-reporting of adverse drug reactions: a systematic review. Drug Saf. 2009;32(1):19-31,

6. Radhakrishnan R, Sudha V, Danturulu MV. An educational intervention to assess knowledge attitude practice of pharmacovigilance among health care professionals in an Indian tertiary care teaching hospital. Int J Pharm Tech Res. 2011;3:678-92. 
7. Lohit K, Vidya KR, Manjunath GN. Development and Validation of Questionnaire to Assess the Knowledge, Attitude and Practice towards Adverse Drug Reactions Reporting among Healthcare Professionals. Journal of International Medicine and Dentistry. 2016;3(2):6372.

8. Kharkar M, Bowalekar S. Knowledge, attitude and perception/practices (KAP) of medical practitioners in India towards adverse drug reaction (ADR) reporting. PerspectClin Res. 2012;3:90-4.

9. Ramesh M, Parthasarathi G. Adverse drug reactions reporting: attitudes and perceptions of medical practitioners. Asian J Pharm Clin Res. 2009;2:10-4.

10. Gupta P, Udupa A. Adverse drug reaction reporting and pharmacovigilance: Knowledge, attitudes and perceptions among resident doctors. J Pharm Sci Res. 2011;3:1064-9.

11. Ghosh S, Ali S, Chhabra L, Prasad C, Gupta A. Investigation of attitudes and perception of medical practitioners on adverse drug reaction reporting: a pilot study. T Ph Res. 2010;3:1-9.

12. Sencan N, Altinkaynak M, Ferah I, Ozyildirim A, Ceylan EM, Clark PM. The knowledge and attitudes of physicians and nurses toward adverse event reporting and the effect of pharmacovigilance training: A hospital experience. Hacettepe University J Faculty Pharm. 2010;30(1):25-40.

13. Green CF, Mottram DR, Rowe PH, Pirmohamed M. Attitudes and knowledge of hospital pharmacists to adverse drug reaction reporting. Br J ClinPharmacol. 2001;51(1):81-6.

14. Khan SA, Goyal C, Chandel N, Rafi M. Knowledge, attitude and practice of doctors to adverse drug reaction reporting in a teaching hospital in India: An observational study. J Nat Sci Biol Med. 2013;4:1916.

15. Remesh A. Identifying the reasons for under reporting of ADR: A cross sectional survey. Res J Pharm BiolChem Sci. 2012;3:1379-86.

Cite this article as: Kunnoor NS, Sharanabasappa, Lohit K. Perception of doctors towards Adverse Drug Reaction (ADR) reporting: a cross sectional survey using a validated questionnaire. Int J Basic Clin Pharmacol 2017;6:2671-5. 